\title{
Produção e qualidade do leite na bacia leiteira de Pelotas-RS em diferentes meses do ano
}

\author{
Milk production and quality at the dairy region of Pelotas, Rio Grande do Sul State \\ at different months of the year
}

\author{
Paulo Ricardo Garcia Martins ${ }^{1}$ Cristiane Andrade da Silva ${ }^{1}$ Vivian Fischer $^{2}$ \\ Maria Edi Rocha Ribeiro ${ }^{3}$ Waldyr Stumpf Júnior ${ }^{3}$ Maira Balbinotti Zanela ${ }^{3}$
}

\section{RESUMO}

Avaliou-se a variação da produção e qualidade do leite, durante 11 meses do ano através do monitoramento de nove unidades produtoras de leite (UP), escolhidas aleatoriamente por pertencerem à bacia leiteira de Pelotas. Foram realizadas coletas mensais de leite e dos alimentos de cada UP. Foram avaliadas as características físico-químicas $e$ contagem de células somáticas do leite, além da incidência de mastite e a produção média de leite das UP. As UP foram classificadas nos seguintes sistemas de produção: especializadas, semi-especializadas e não especializadas conforme critérios previamente estabelecidos. Na análise da variância, foram considerados os efeitos de sistemas de produção, meses do ano e a interação entre sistemas e meses do ano, segundo um delineamento completamente casualizado em arranjo fatorial. Foram observadas diferenças no leite produzido nos diversos meses do ano, quanto à produção de leite corrigida, proteína bruta, teor de caseína, teor de lactose, extrato seco total, extrato seco desengordurado e incidência de mastite, não sendo observadas, neste estudo, diferenças quanto às percentagens de gordura e nitrogênio não protéico do leite nem contagem de células somáticas. Nos meses de outono e inverno, ocorreram as menores produções de leite e menores teores dos componentes químicos, enquanto a ocorrência de mastite foi mais importante nos meses de primavera - verão.

Palavras-chave: características físico-químicas do leite, contagem de células somáticas, mastite, produção de leite

\section{ABSTRACT}

We evaluated changes in milk production and quality during 11 months in nine milk production units, randomly chosen at the Pelotas dairy region. Mastitis incidence and average milk daily production were registered. Once a month, animal feed and bulk milk samples were collected at each production unit for further physical-chemical analysis and somatic cells count. Production units were classified in one of the following production systems: specialized, semi-specialized and not specialized. Analysis of variance was used to evaluate the effects of months, production systems and their interaction, according to a completely randomized design. Fat corrected milk production, crude protein, casein, lactose, total solids, solids non fat contents of the milk and mastitis incidence varied among months, but fat and non protein nitrogen contents and somatic cells count did not. In fall and winter, values for milk production and milk components contents were the lowest, while mastitis incidence was highest in spring and summer.

Key words: mastitis, milk physical-chemical characteristics, milk production, somatic cells count

\section{INTRODUÇÃO}

As dificuldades enfrentadas pelo setor leiteiro, devido à baixa produtividade aliada a altos custos, resultam em parte, da existência desde produtores "extrativistas" que adotam pouca ou nenhuma tecnologia, até produtores altamente especializados (JANK et al., 1999), sendo encontrados sistemas intermediários de produção, entre os quais, modelos intensivos de utilização de pastagens (BRESSAN \& VILELA, 1999).

O Rio Grande do Sul apresenta uma grande diversidade edafoclimática e condições propícias para

\footnotetext{
${ }^{1}$ Autônomo, Pelotas, RS, Brasil.

${ }^{2}$ Departamento de Zootecnia, Agronomia, Universidade Federal do Rio Grande do Sul, Rua Fernandes Vieira 181/601, 90035-091, Porto Alegre, RS, Brasil.

${ }^{3}$ Empresa Brasileira de Pesquisa Agropecuária (EMBRAPA), Pelotas, RS, Brasil.
} 
o desenvolvimento da pecuária leiteira com animais de raças especializadas como Holandês e Jersey. Observam-se, no entanto, acentuadas variações de temperatura do ar e do solo entre os períodos de inverno e de verão, distribuição irregular da precipitação pluviométrica, com consequientes variações sazonais nas taxas de crescimento das forrageiras (STUMPF et al., 2000). A maioria dos produtores de leite desenvolve sua atividade em áreas predominantemente não superiores a 20 hectares e tem, como maior fator de estrangulamento da produção, a falta de reserva alimentar (volume e qualidade) nos meses de março, abril e novembro de cada ano (BITTENCOURT et al., 2000).

Apesar de não estarem relacionados com a qualidade intrínseca do leite, o volume e a sazonalidade de produção são critérios considerados para o pagamento do produto, pois interessa aos laticínios captar leite junto aos produtores que forneçam grandes volumes diários de leite e que apresentem pequena variação sazonal da produção (FONSECA, 2001).

É crescente a preocupação com a qualidade dos produtos de origem animal em outros países (MONARDES, 2004), embora relativamente incipiente no Brasil. A qualidade do leite pode ser definida em termos de sua integridade, ou seja, sem sofrer adição de substâncias e/ou remoção de componentes; de sua composição química, características físicas e livre de deterioração microbiológica e presença de patógenos (DÜRR, 2004).

Existem iniciativas governamentais visando padronizar e melhorar a qualidade do leite, como a implantação de normas nacionais de padrões de qualidade de leite, determinadas pelo Programa Nacional de Melhoria da Qualidade de Leite, do Ministério da Agricultura (RIBEIRO et al., 2000) e pela Normativa 51 já em vigor (BRASIL, 2002).

O presente trabalho teve por objetivo estudar as variações sazonais da produção e características físico-químicas do leite na bacia leiteira de Pelotas, RS ao longo de onze meses do ano em diferentes sistemas de produção.

\section{MATERIAL E MÉTODOS}

Este trabalho foi conduzido pelo grupo de pesquisas "Estudos em Pecuária Leiteira, da Universidade Federal de Pelotas", em conjunto com a Embrapa-Clima Temperado, em nove unidades de produção (UP) pertencentes à bacia leiteira de Pelotas. Foram realizadas coletas mensais de leite, no período de 01/09/2001 à 31/08/2002 (com exceção do mês de janeiro, devido às férias). Ao final do período de coleta de dados, as UPs foram classificadas em três sistemas de produção: sistema especializado (ES), semiespecializado (SE) e não-especializado (NE), determinados em função da quantidade e da disponibilidade de volumoso e de concentrado fornecidos, da infra-estrutura, do recebimento de assistência técnica e do tipo de ordenha.

A categoria ES foi constituída por três UPs, sendo uma composta de um rebanho da raça Jersey e as demais da raça Holandês, com animais especializados e selecionados à produção leiteira. Possuem sala de ordenha tipo espinha de peixe, com circuito fechado, sala de espera pavimentada e sistema de limpeza dos equipamentos automatizado. Utilizam medidas de controle de mastite como caneca de fundo preto, préimersão em solução desinfetante, secagem dos tetos com papel toalha descartável, pós-imersão, descarte de animais portadores de mastite crônica. Utilizam alimentação relativamente constante ao longo do ano à base de concentrado com teor de proteína bruta médio de $16,80 \%$, silagem de milho ou sorgo e pastagem cultivada de forma intensiva, especialmente de aveia preta (Avena strigosa, Schreb) e azevém anual (Lolium multiflorum, Lam). As vacas foram inseminadas ou cobertas durante todo o ano à medida que apresentaram cio, não havendo uma época definida ou restrita de parições.

A categoria SE foi constituída de UPs constituídas da seguinte forma: uma composta por rebanho da raça Jersey e as demais da raça Holandês, sendo os animais considerados de boa aptidão leiteira. Duas UPs possuem sala de ordenha espinha de peixe, com circuito fechado e duas utilizam o sistema de balde ao pé. Nem todas as UPs utilizam todas as medidas de controle de mastite recomendadas. Utilizam alimentação à base de concentrado, silagem de milho ou sorgo e pastagem de azevém anual (Lolium multiflorum, Lam), porém sem manter a qualidade e constância durante o ano. As vacas foram inseminadas ou cobertas durante todo o ano à medida que apresentaram cio, não havendo uma época definida ou restrita de parições.

A categoria NE foi constituída de duas UPs, sendo uma composta por rebanho da raça Jersey e a outra por rebanho da raça Holandês, possuindo animais pouco especializados para produção leiteira. As duas unidades de produção utilizam o sistema de balde ao pé. As medidas de controle de mastite não são utilizadas ou apresentam-se inadequadas. Não utilizam ração balanceada, nem silagem ou pastagem cultivada regularmente, e as condições nutricionais e sanitárias são deficientes durante a maior parte do ano. As vacas foram cobertas durante todo o ano à medida que apresentaram cio, não havendo uma época definida ou restrita de parições. 
As amostras de leite foram coletadas do tanque resfriador, após a ordenha da tarde, e encaminhadas ao Laboratório de Nutrição Animal (LNA), do Departamento de Zootecnia da Universidade Federal de Pelotas e para o Serviço de Análise de Rebanhos Leiteiros (Sarle), da Universidade de Passo Fundo para a realização das análises físico-químicas.

No início da ordenha, foram realizados testes da caneca de fundo preto e o Califórnia Mastitis Test (CMT), para detecção de quartos com mastite subclínica (SCHALM \& NOORLANDER, 1957). O percentual de mastite (MAS) foi calculado através da divisão do número de quartos positivos ao teste de CMT pelo número total de quartos analisados, em cada UP e a cada mês.

A avaliação das características químicas e físicas do leite foi feita pela determinação da acidez segundo o método de Dornic, $\left({ }^{\circ} \mathrm{D}\right)$, a gordura foi medida através do butirômetro de Gerber (FAGUNDES, 1997), o extrato seco total (EST) foi determinado através do método de Ackermann (TRONCO, 1997), e o extrato seco desengordurado (ESD) foi calculado pela diferença entre a percentagem de gordura e extrato seco total (TRONCO, 1997). Os teores de nitrogênio não protéico (NNP) e proteína bruta (PB) foram determinados pelo método de Kjedahl (SILVA et al., 1997). A porcentagem de caseína (CAS) foi determinada através do método de Walker, utilizando $\mathrm{NaOH} 0,1 \mathrm{~N}$ e formaldeído (FAGUNDES, 1997). O teor de lactose (LACT) foi determinado através de espectrofotometria por radiação infravermelha no equipamento Bentley 2000® (FONSECA \& SANTOS, 2000). Os valores dos componentes químicos do leite foram apresentados como porcentagem. A crioscopia (CRIO) do leite foi medida através de Crioscópio Eletrônico Digital ITR MK540, fornecendo a leitura em Graus Horvet (TRONCO, 1997).

Nas amostras de leite enviadas ao Serviço de Análise de Rebanhos Leiteiros (Sarle), da Universidade de Passo Fundo (UPF), realizou-se a contagem de células somáticas (CCS) em contador eletrônico pela citometria de fluxo (Somacount 300, da Bentley Instruments, Inc.). Os resultados foram expressos como $\mathrm{n}^{\mathrm{o}} \mathrm{x} 1000$ células somáticas/ml de leite.

Foram coletadas amostras de todos os alimentos (concentrados, pastagem e silagem) utilizados no dia da coleta, e foram analisadas aquelas relativas aos meses de outubro, março e agosto, por se julgar que esses meses seriam representativos da primavera, final do verão e inverno. No LNA, realizouse a pré-secagem das amostras, em estufa com circulação forçada de ar, à temperatura de $60^{\circ} \mathrm{C}$ por 48 horas, seguida por moagem em moinho tipo Willey.
Posteriormente foram analisadas quanto à proteína bruta, segundo o AOAC (1975), de fibra em detergente ácido e fibra em detergente neutro (GOERING \& VAN SOEST, 1970).

Os dados mensais climatológicos (Tabela 1), usados neste trabalho, foram obtidos na Estação Agroclimatológica de Pelotas (BOLETIM AGROCLIMATOLÓGICO, 2001 e 2002).

$\mathrm{O}$ delineamento experimental adotado foi o completamente casualizado em arranjo fatorial desbalanceado (MARKUS, 1973), considerando como fatores os meses do ano $(n=11)$, os sistemas de produção $(n=3)$ e a sua interação. As UPL dentro de cada sistema foram as unidades experimentais. As variáveis dependentes analisadas foram os valores porcentuais dos componentes químicos do leite, crioscopia, acidez, produção de leite corrigida para $4 \%$ de gordura, porcentagem de mastite, contagem de células somáticas. A produção de leite do tanque foi corrigida para $4,0 \%$ de gordura $[(0,4) \times$ (produção de leite) +15 (produção de leite $x \%$ gordura/100)] (NRC, 2001).

As variáveis expressas como porcentagens foram transformadas pela aplicação do arcoseno da raiz quadrada de seus valores percentuais e posteriormente analisados (MARKUS, 1973). Os valores de contagem de células somáticas foram transformados pela aplicação do logaritmo base 10 e posteriormente analisados (NG-KWAI-HANG et al., 1982). Embora a análise estatística tenha sido feita com os valores transformados, os seus valores originais são apresentados nas tabelas que seguem, para facilitar a interpretação.

Apesar do efeito de sistemas de produção e sua interação com os meses do ano terem sido considerados no modelo estatístico, os resultados relativos a este efeito não são apresentados neste trabalho, e serão abordados posteriormente em outro manuscrito.

\section{RESULTADOS E DISCUSSÃO}

Não houve efeito significativo da interação entre meses e sistemas de produção sobre as variáveis dependentes $(\mathrm{P}>0,05)$. No presente trabalho, serão mostrados apenas os efeitos dos meses do ano sobre a produção e as características do leite.

A produção de leite corrigida para 4\% (PLC) de gordura variou entre os meses estudados $(\mathrm{P}<0,001)$, os valores superiores foram encontrados nos meses de setembro e outubro, enquanto os inferiores foram observados nos meses de dezembro, março, abril, maio, junho, julho e agosto (Tabela 1). Embora as datas exatas 
Tabela 1 - Valores mensais históricos (posição superior) e do ano 2001/2002 (posição inferior) de temperatura média (TH) (TM) em ${ }^{\circ} \mathrm{C}$, temperaturas médias das mínimas (TMMiH) (TMMia) em ${ }^{\circ} \mathrm{C}$, temperatura média das máximas (TMMaH) $\left(\mathrm{TMMa}\right.$ em ${ }^{\circ} \mathrm{C}$, precipitação pluviométrica (PPH) (PPM) em mm, número de dias de precipitação (NDPH) (NDP), da produção de leite corrigida para 4\% de gordura (PLC, em $1 /$ vaca/dia) e dos percentuais de proteína bruta (PB, \%), caseína (CAS, \%), gordura bruta (GB, \%), lactose (LACT, \%), extrato seco total (EST, \%), extrato desengordurado (ESD, \%) e nitrogênio não protéico (NNP, \%), valores de contagem de células somáticas (CCS, valores x 1000 células/ml leite), acidez (ACI, ${ }^{\circ}$ Dornic), incidência de mastite (MAS, \%) e crioscopia (CRIO, $\left.{ }^{\circ} \mathrm{H}\right)$, de acordo com o mês de coleta de leite (setembro/2001 a agosto/2002)

\begin{tabular}{|c|c|c|c|c|c|c|c|c|c|c|c|}
\hline \multirow[t]{2}{*}{ Itens } & \multicolumn{11}{|c|}{ Meses } \\
\hline & set & out & nov & dez & fev & mar & $\mathrm{abr}$ & mai & jun & jul & ago \\
\hline TH & 15,1 & 17,6 & 19,7 & 22,0 & 23,0 & 21,7 & 18,5 & 15,1 & 12,4 & 12,3 & 13,4 \\
\hline $\mathrm{TM}$ & 15,7 & 19,4 & 20,0 & 21,2 & 22,1 & 24,0 & 19,1 & 17,4 & 13,0 & 12,5 & 14,5 \\
\hline TMMH & 11,6 & 14,0 & 14,8 & 17,8 & 18,6 & 17,0 & 10,0 & 12,2 & 11,8 & 7,3 & 8,0 \\
\hline TMMia & 11,2 & 13,2 & 15,0 & 17,2 & 18,7 & 17,2 & 13,8 & 10,6 & 8,4 & 8,6 & 9,4 \\
\hline TMMH & 19,7 & 20,9 & 24,5 & 26,4 & 27,8 & 25,6 & 25,1 & 20,0 & 19,4 & 15,4 & 18,2 \\
\hline TMMa & 19,4 & 22,1 & 24,4 & 26,9 & 28,2 & 26,7 & 23,7 & 20,8 & 17,9 & 17,6 & 18,3 \\
\hline PPH & 137,2 & 94,5 & 96,4 & 91,9 & 153,3 & 97,4 & 100,3 & 100,7 & 105,7 & 146,0 & 117,4 \\
\hline PPM & 229,4 & 66,6 & 203,8 & 124,5 & 137,1 & 349,4 & 248,2 & 128,8 & 144,6 & 109,4 & 187,2 \\
\hline $\mathrm{NDPH}$ & 10,8 & 9,7 & 9,5 & 9,1 & 15,0 & 10,3 & 8,9 & 9,2 & 10,5 & 11,4 & 9,7 \\
\hline NDP & 12,0 & 17,0 & 11,0 & 9,0 & 11,0 & 20,0 & 16,0 & 12,0 & 9,0 & 11,0 & 13,0 \\
\hline PLC & $12,2 \mathrm{ab}$ & $13,0 \mathrm{a}$ & $10,6 b c$ & $10 \mathrm{~cd}$ & $10,2 b c$ & $8,8 \mathrm{~cd}$ & $8,5 \mathrm{~cd}$ & $7,4 d$ & $8,7 \mathrm{~cd}$ & $7,7 \mathrm{~d}$ & $8,8 \mathrm{~cd}$ \\
\hline PB & $3,25 \mathrm{a}$ & $3,18 \mathrm{a}$ & $3,19 \mathrm{a}$ & $3,12 \mathrm{a}$ & $3,1 \mathrm{ab}$ & $3,24 \mathrm{a}$ & $3,20 \mathrm{a}$ & $3,16 \mathrm{a}$ & $3,18 \mathrm{a}$ & $2,82 \mathrm{c}$ & $2,9 b c$ \\
\hline CAS & $2,71 \mathrm{a}$ & $2,76 a$ & $2,71 \mathrm{a}$ & $2,76 a$ & $2,52 b$ & $2,45 b$ & $2,44 b$ & $2,43 b c$ & $2,48 b$ & $2,25 \mathrm{~d}$ & $2,3 \mathrm{~cd}$ \\
\hline GB & 3,45 & 3,44 & 3,21 & 3,19 & 2,81 & 3,09 & 3,45 & 3,28 & 3,63 & 3,23 & 3,22 \\
\hline LACT & $4,45 \mathrm{ab}$ & $4,52 \mathrm{a}$ & $4,55 \mathrm{a}$ & $4,50 \mathrm{ab}$ & $4,4 \mathrm{bc}$ & $4,3 b c$ & $4,16 \mathrm{~d}$ & $4,11 \mathrm{~d}$ & $4,08 \mathrm{~d}$ & $4,16 \mathrm{~d}$ & $4,35 b$ \\
\hline EST & $12,05 \mathrm{a}$ & $11,97 \mathrm{a}$ & $11,68 \mathrm{abcd}$ & 11,61abcde & $11,25 \mathrm{e}$ & $11,41 \mathrm{cde}$ & $11,77 \mathrm{abc}$ & 11,48 bcde & $11,89 \mathrm{ab}$ & $11,24 \mathrm{de}$ & $11,41 \mathrm{bcde}$ \\
\hline ESD & $8,61 \mathrm{a}$ & $8,53 \mathrm{ab}$ & $8,5 \mathrm{abc}$ & $8,4 \mathrm{abcd}$ & $8,4 \mathrm{abc}$ & $8,3 \mathrm{bcd}$ & $8,3 \mathrm{bcd}$ & $8,27 \mathrm{~cd}$ & $8,2 \mathrm{de}$ & $8,0 \mathrm{e}$ & $8,2 \mathrm{cde}$ \\
\hline NNP & 0,033 & 0,037 & 0,034 & 0,04 & 0,034 & 0,034 & 0,031 & 0,039 & 0,034 & 0,038 & 0,035 \\
\hline CCS & 399 & 316 & 357 & 390 & 264 & 334 & 317 & 386 & 402 & 332 & 350 \\
\hline ACI & $17,5 \mathrm{a}$ & $17,4 \mathrm{a}$ & $17,1 \mathrm{~b}$ & $16,4 \mathrm{bc}$ & $16,5 \mathrm{bc}$ & $16,0 \mathrm{~cd}$ & $15,6 \mathrm{~cd}$ & $15,5 \mathrm{~cd}$ & $15,2 \mathrm{~d}$ & $15,5 \mathrm{~cd}$ & $15,1 \mathrm{~d}$ \\
\hline MAS & $68,0 \mathrm{a}$ & $62,6 \mathrm{a}$ & $64,9 \mathrm{a}$ & $66,7 \mathrm{a}$ & $38 \mathrm{bc}$ & $43,2 b$ & $43 b c$ & $50,1 \mathrm{~b}$ & $45,9 \mathrm{~b}$ & $47,6 b$ & $32 \mathrm{c}$ \\
\hline CRIO & $-0,537 b c$ & $-0,553 c$ & $-0,536 b c$ & $-0,558 \mathrm{a}$ & $-0,546 b$ & $-0,544 b c$ & $-0,542 b c$ & $-0,539 b c$ & $-0,542 b c$ & $-0,539 b c$ & $-0,540 b c$ \\
\hline
\end{tabular}

a,b,c,d,e = Médias na mesma linha seguidas por letras distintas diferem entre si de acordo com o teste DMS Fisher $(\alpha=0,050)$

dos partos não tenham sido fornecidas, observou-se uma distribuição relativamente uniforme de parições ao longo do ano, em todas as UPL, não havendo um ou mais meses com parições concentradas. Como a pastagem é a base alimentar da maioria das unidades produtoras de leite da região, melhores condições nutricionais resultantes de uma melhor qualidade (Tabela 2) e disponibilidade forrageira ocorrida em outubro explicariam a maior produção de leite. Em agosto, apesar da pastagem apresentar boa qualidade, observou-se reduzida disponibilidade de forragem, apesar de não se tê-la quantificado. Em outro estudo, a restrição alimentar provocou a redução em $26 \%$ da produção de leite (ZANELA, 2004). Na bacia leiteira de Pelotas, entre setembro de 1999 a agosto de 2000, GONZALES et al. (2004) encontraram uma PLC de 11,48 +/- 1,91 1/vaca/dia, mas não detectaram diferenças significativas entre os meses, atribuindo o fato ao pequeno número de unidades de produção estudadas.

Houve diferenças significativas $(\mathrm{P}<0,05)$, entre os meses do ano, para os valores percentuais de PB, LACT, CAS, EST, ESD do leite, porcentagem de quartos mamários com mastite, valores de CRIO e acidez. Não houve diferenças significativas $(\mathrm{P}>0,05)$ entre os meses para os teores no leite de GB, NNP e valores de CCS. Os valores mínimos de PB e CAS ocorreram em julho e agosto, os de ESD em junho, julho e agosto, enquanto os de EST ocorreram em fevereiro e julho, embora sem diferir estatisticamente dos meses de dezembro, março, maio e agosto. Os menores valores de LACT foram observados, entre abril e julho, coincidindo com alguns dos menores valores de PLC, com o excesso de precipitação (Tabela 1) e época de déficit nutricional. Em julho, o teor de PB foi inferior ao preconizado pela Normativa 51, o qual é de 2,9\% (BRASIL, 2002). Os maiores valores de PB, CAS e LACT ocorreram nos meses de primavera e início do verão, coincidindo com a melhoria das condições climáticas e maior oferta e qualidade das pastagens (Tabelas 1 e 2).

Segundo PERES (2001), entre os fatores que reduzem o teor de proteína no leite estão: o baixo consumo de matéria seca, falta de proteína degradável, falta de carboidratos não estruturais, etc. Os valores de PB e GB do leite do presente trabalho são semelhantes àqueles verificados por DÜRR (2003). No 
Tabela 2 - Valores médios da composição química da dieta, agrupados por categorias sistemas de produção no início, meio e fim do período de estudo (valores expressos como percentagem da matéria seca do alimento)

\begin{tabular}{|c|c|c|c|c|c|c|c|c|c|}
\hline & \multicolumn{3}{|c|}{ outubro } & \multicolumn{3}{|c|}{ março } & \multicolumn{3}{|c|}{ agosto } \\
\hline & $\mathrm{ES}^{4}$ & $\mathrm{SE}^{5}$ & $\mathrm{NE}^{6}$ & $\mathrm{ES}^{4}$ & $\mathrm{SE}^{5}$ & $\mathrm{NE}^{6}$ & $\mathrm{ES}^{4}$ & $\mathrm{SE}^{5}$ & $\mathrm{NE}^{6}$ \\
\hline \multicolumn{10}{|c|}{ Pastagem } \\
\hline $\mathrm{PB}^{1}$ & 12,30 & 9,56 & 9,40 & 9,63 & 8,23 & 8,19 & 13,03 & 14,64 & 12,85 \\
\hline $\mathrm{FDN}^{2}$ & 57,82 & 60,97 & 63,56 & 71,38 & 72,51 & 74,27 & 56,68 & 58,48 & 61,25 \\
\hline $\mathrm{FDA}^{3}$ & 40,87 & 46,96 & 43,79 & 41,42 & 40,22 & 41,04 & 36,67 & 31,13 & 43,73 \\
\hline \multicolumn{10}{|c|}{ Concentrado } \\
\hline $\mathrm{PB}^{1}$ & 15,12 & 15,68 & 15,01 & 18,59 & 16,47 & 14,36 & 16,70 & 15,01 & 14,05 \\
\hline $\mathrm{FDN}^{2}$ & 30,86 & 36,86 & 37,13 & 43,86 & 44,25 & 41,11 & 33,70 & 35,95 & 36,28 \\
\hline $\mathrm{FDA}^{3}$ & 9,23 & 8,07 & 16,64 & 11,10 & 16,40 & 17,23 & 13,72 & 16,78 & 14,59 \\
\hline \multicolumn{10}{|c|}{ Silagem } \\
\hline $\mathrm{PB}^{1}$ & 5,74 & - & - & 6,90 & - & - & 6,02 & - & - \\
\hline $\mathrm{FDN}^{2}$ & 62,03 & - & - & 64,13 & - & - & 61,72 & - & - \\
\hline $\mathrm{FDA}^{3}$ & 33,85 & - & - & 33,93 & - & - & 38,07 & - & - \\
\hline
\end{tabular}

${ }^{1}$ Proteína Bruta (PB), valores expressos como porcentagem da matéria seca

${ }^{2}$ Fibra em detergente neutro (FDN), valores expressos como porcentagem da matéria seca

${ }^{3}$ Fibra em detergente ácido (FDA), valores expressos como porcentagem da matéria seca

${ }^{4} \mathrm{SE}$ - Sistema Especializado

${ }^{5} \mathrm{SE}$ - Sistema Semi especializado

${ }^{6} \mathrm{NE}$ - Sistema Não Especializado

entanto, os valores mínimos de LACT, encontrados no presente trabalho, são inferiores aos encontrados por DÜRR (2003), de 4,35 a 4,66\%, no ano de 2002. O autor associou os menores valores de PB, GB e LACT ao menor fornecimento de concentrado e/ou uso de dietas desequilibradas, em função dos preços baixos do leite recebido pelos produtores. Na bacia leiteira de Pelotas, vacas Jersey em restrição alimentar apresentaram redução no teor de proteína bruta do leite de 4,04 para $3,89 \%$ (ZANELA, 2004).

Nos meses de março a agosto, os valores de ESD apresentaram-se abaixo dos valores permitidos (mínimo de 8,4\%) pela Normativa 51 (BRASIL, 2002). Na bacia leiteira de Pelotas, entre abril de 2002 a julho de 2003, ZANELA (2004) verificou que, de 1735 amostras de leite recebidas pela cooperativa local, $25 \%$ e $65 \%$ apresentavam, respectivamente, valores de $\mathrm{PB}$ e de ESD abaixo dos recomendados pela Normativa 51. Como a porcentagem de ESD abaixo dos limites da Normativa 51, foi maior que a da PB, o baixo teor de ESD possivelmente esteja relacionado ao baixo teor de LACT, cuja redução foi associada à subnutrição do rebanho (ZANELA, 2004).

Em acordo com os resultados encontrados no presente trabalho, GONZALES et al. (2004), na bacia leiteira de Pelotas, encontraram que os teores de GB e NNP, além da CCS, não variaram entre os meses estudados. Os autores verificaram amplitude de valores para GB, NNP e CCS, respectivamente, de 3,5 a 3,86\%, 0,024 a $0,033 \%$ e 307 a 693 x 1000 células/ml, os quais foram, respectivamente, superiores, inferiores e superiores aos do presente trabalho.

A acidez titulável (ACI) e a crioscopia (CRIO) apresentaram valores que diferiram entre os meses avaliados $(\mathrm{P}<0,05)$, embora se mantivessem dentro dos valores considerados normais pela Normativa 51 (BRASIL, 2002) (Tabela 1). Na bacia leiteira de Pelotas, GONZALES et al. (2004) não encontraram diferenças entre os meses para crioscopia, mas verificaram valores de acidez entre 14,95 e $17,5^{\circ} \mathrm{D}$, os quais foram semelhantes aos do presente trabalho.

Os maiores valores de MAS ocorreram entre setembro e dezembro de 2001, enquanto os valores inferiores ocorreram em fevereiro, abril e agosto 2002 (Tabela 1). Este fato seria explicado pelo melhor manejo de ordenha das unidades de produção no decorrer do estudo, favorecendo a menor incidência de mastite (HARMON, 1994) e pela segregação dos animais com problema crônico de mastite. Aparentemente não houve efeito do número de dias de chuva ou da precipitação, pois esses valores numéricos não diferiram entre os meses com maiores e menores valores de MAS. Na bacia leiteira de Pelotas, a melhoria das condições higiênicas, durante a ordenha e a retirada dos animais com mastite clínica, contribuíram para a redução do percentual de quartos positivos ao CMT de 55 para 
30\% (ZANELA, 2004). GONZALES et al. (2004) encontraram uma incidência de MAS semelhante ao presente trabalho, 56,61 +/- 11,61\%, com os maiores valores em novembro e maio, e os menores em setembro, outubro, julho e agosto.

\section{CONCLUSÕES}

Os teores da composição química do leite variaram em função dos meses do ano, relacionados, parcialmente, às variações da qualidade dos alimentos. De modo geral, o melhor nível nutricional, verificado na primavera, permitiu os maiores valores das frações nitrogenadas do leite. Os teores de PB do leite produzido em julho e agosto; de GB em fevereiro e de ESD nos meses de março, abril, maio, junho, julho e agosto estariam fora dos padrões exigidos pela Instrução Normativa 51.

\section{AGRADECIMENTOS E APRESENTAÇÃO}

Ao Conselho Nacional de Desenvolvimento Científico e Tecnológico (CNPq), pela concessão da bolsa de pesquisa a Fisher.

Trabalho de pesquisa financiado pelo Programa de Pós-graduação em Zootecnia (PPGZ) da Universidade Federal de Pelotas (UFPEL), Embrapa-Clima Temperado (CPACT)

\section{REFERÊNCIAS}

ASSOCIATION OF OFFICIAL ANALITICAL CHEMISTAOAC. Official methods of analysis. 12.ed. Washigton, DC, 1975. 1094p.

BITTENCOURT, D. et al. A importância da atividade leiteira na economia agropecuária do RGS. In: STUMPF, W.J. et al. Sistemas de pecuária de leite: uma visão na região de clima temperado. Pelotas: Embrapa Clima Temperado, 2000. $195 \mathrm{p}$.

BOLETIM AGROCLIMATOLÓGICO. Estação Agroclimatologia de Pelotas. Pelotas: EMBRAPA/UFPEL, 2001 e 2002. 36p.

BRASIL. Instrução Normativa n.51 de 18 de setembro de 2002. Ministério da Agricultura e do Abastecimento, Secretaria de Defesa Agropecuária, 2002.

BRESSAN, M.; VILELA, D. (Ed.). Restrições técnicas, econômicas e institucionais ao desenvolvimento da cadeia produtiva do leite no Brasil: Região Sul. Brasília: Embrapa - CNPGL, 1999. 58f

DÜRR, J.W. Panorama da qualidade do leite na região Sul (RS). In: BRITO, I.R.F. et al. Diagnóstico da qualidade do leite, impacto para industria e a questão dos resíduos de antibióticos. Juiz de Fora: Embrapa, 2003, $168 \mathrm{f}$.

DÜRR, J.W. Programa nacional de melhoria da qualidade do leite: uma oportunidade única. In: DÜRR, J.W. et al. (Ed.). O compromisso com a qualidade do leite no Brasil. Passo Fundo: UPF, 2004. 331p.

FAGUNDES, C.M. Inibidores e controle da qualidade do leite. Pelotas: UFPEL, 1997. 126p.

FONSECA, L.F.L.; SANTOS, M.V. Qualidade do leite e controle de mastite. São Paulo: Lemos, 2000. 175p.
FONSECA, L.F.L. Critérios no pagamento por qualidade. Revista Balde Branco, v.37, n.444, p.28-34, 2001.

GOERING, H.K.; VAN SOEST, P.J. Forage fiber analysis (apparatus, reagents, procedures and some aplications). Whashington, DC: Agric. Res. Seervice. U.S. Dep. Agric., 1970. 379 f.

GONZALES, H.L et al. Avaliação da qualidade do leite nos diferentes meses do ano na bacia leiteira de Pelotas, RS. Revista Brasileira de Zootecnia, v.33, n.6, p.1531-1543, 2004.

JANK, M.S. et al. O agribusiness do leite no Brasil. São Paulo: Milkbizz, 1999. 108p.

HARMON, R.J. Symposium: mastitis and genetic evaluation for somatic cell count. Journal of Dairy Science, v.77, n.7, p.2103-2111, 1994.

MARKUS, R. Elementos da estatística aplicada. Porto Alegre: Faculdade de Agronomia, Universidade Federal do Rio Grande do Sul, Diretório Acadêmico Leopoldo Cortês, 1973. 329 p.

MONARDES, H. Reflexões sobre a qualidade do leite. In: DÜRR, J.W. et al. (Ed.). O compromisso com a qualidade do leite no Brasil. Passo Fundo: UPF, 2004. 331p.

NATIONAL RESEARCH COUNCIL - NRC. Nutrient requirements of dairy cattle. 7.ed. Washington, DC: National Research Council. National Academic, 2001. 381p.

NG-KWAI-HANG, K.F. et al. Environmental influences on protein content and composition of bovine milk. Journal of Dairy Science, v.65, p.1993-1998. 1982.

PERES, J.R. O leite como ferramenta do monitoramento nutricional. In: GONZALEZ, F.H.D. et al. Uso do leite para monitorar a nutrição e metabolismo de vacas leiteiras. Porto Alegre: Universidade Federal do Rio Grande do Sul, 2001. p. $29-43$.

RIBEIRO, M.E.R et al. Manejo de ordenha e mastite. In: STUMPF, W.J. et al. Sistemas de pecuária de leite: uma visão na região de clima temperado. Pelotas: Embrapa Clima Temperado, 2000. 195p

SCHALM, O.W.; NOORLANDER, D.O. Experimental and observation lading to development of California Mastitis Test. Journal Animal Veterinary Medical, v.130, p.199-204. 1957.

SILVA, P.H.F. et al. Físico - química do leite e derivados - métodos analíticos. Juiz de Fora: Oficina de Impressão, 1997. 190p.

STUMPF, W.J. et al. Sistema de produção. In: STUMPF, W.J. et al. Sistemas de pecuária de leite: uma visão na região de clima temperado. Pelotas: Embrapa Clima Temperado, 2000. 195p.

TRONCO, V.M. Manual para inspeção da qualidade do leite. Santa Maria: UFSM, 1997. 166p.

ZANELA, M.B. Caracterização do leite produzido no Rio Grande do Sul, ocorrência e indução experimental do leite instável não-ácido (LINA). 2004. 150f. Tese (Doutorado em Zootecnia - Produção Animal) - Faculdade de Agronomia Eliseu Maciel/ Universidade Federal de Pelotas. 